\title{
OBITUARY
}

\section{VIKTOR NIKOLAEVICH KLIMENKO}

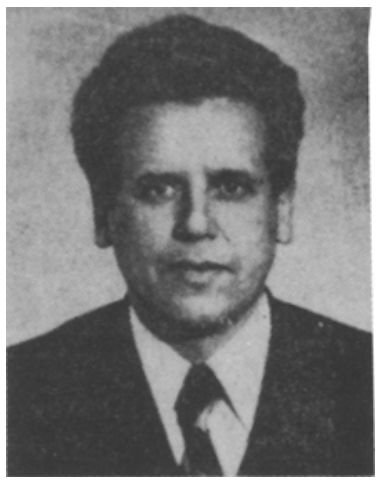

On July 29, 1994 the life of Viktor Nikolaevich Klimenko - an unendingly modest and totally honorable man, sympathetic comrade and stalwart worker, sincerely devoted to the causes which he, in the literal sense, served - came to an end.

Just two years ago, on September 21, 1992, we congratulated him on the occasion of his 60th birthday. The creative activity of V. N. Klimenko was entirely and indissolubly associated with the Institute of the Problems of Materials Science of the National Academy of Sciences of the Ukraine, which he entered as an engineer in 1955. Viktor Nikolaevich departed from the Institute and his life simultaneously. The renowned specialist in the field of powder metallurgy remained at his post, that of Vice Director for Scientific Work of the Institute and Head of the Department of Structural Powder Materials, until the last minute.

It is difficult to speak of Viktor Nikolaevich in the past tense. However, his past is nothing less than the founding and development of the powder metallurgy industry of our country. With his direct participation an entire series of specialized plants and divisions for the production of components by the powder metallurgy method was established. V. N. Klimenko contributed greatly to development of the scientific principles and manufacturing processes for the production of iron powders, and to the organization of mass production facilities for articles based on these at the Brovarskii powder metallurgy plant, for which the scholar was honored with the Ukrainian State, and SSSR Ministerial Council prizes.

In a series of investigations V. N. Klimenko developed the scientific foundations for the production of hard alloys based on chromium carbide, and substantially extended the field of application of these materials. Under his direction, and with his active participation, studies were carried out to develop new iron-based structural powder materials, as well as structural materials for special applications.

The leadership of V. N. Klimenko in the field of international cooperation, and his contributions to the establishment of joint production facilities in Bulgaria and Cuba are well known.

V. N. Klimenko devoted no small effort to developing and promoting the authority of "Poroshkovaya Metallurgiya," and was for many years a member of its Board of Editors.

With the help of Victor Nikolaevich it was possible, even in these difficult times, to retain a large staff at the Institute, maintain ties with other research and production facilities, and develop and establish new relationships, including those of an international nature, in particular with China and India. Thanks again to his participation, new economic structures were created which permit not only the attainment of a worthy position in life, but also bring in profit. V. N. Klimenko departed from life at the height of his creative powers. His position remains empty - some people are truly irreplaceable. 